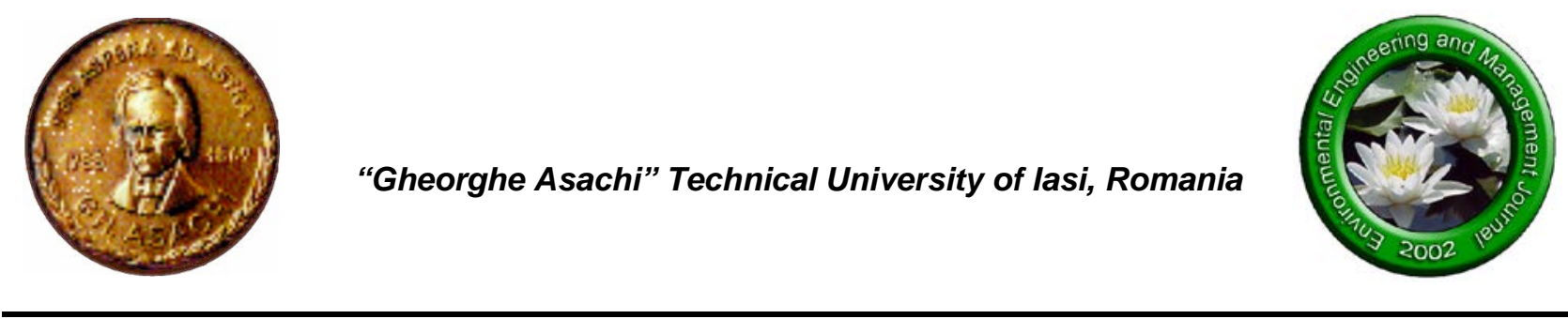

\title{
MEASURING METABOLIC RATE TO IMPROVE COMFORT MANAGEMENT IN BUILDINGS
}

\author{
Andrea Calvaresi, Marco Arnesano*, Filippo Pietroni, Gian Marco Revel
}

Università Politecnica delle Marche, Department of Industrial Engineering and Mathematical Science, Ancona, Italy

\begin{abstract}
Indoor environment significantly affects occupants' health and productivity. However, in smart buildings and cities, it can be improved thanks to the implementation of innovative ICT systems and services. Thermal comfort is one of the most complex aspects to be considered to enhance occupants' well-being, because of the relevant role played by subjective parameters (physiological, psychological and cultural) in its evaluation. This challenge can be tackled by integrating wearable devices into the monitoring framework. Thus, this paper presents an innovative methodology to measure metabolic rate (M) based on wearable devices, which can be used to apply Fanger's comfort model. This model makes use of both environmental and physiological quantities to calculate the PMV (Predicted Mean Vote) index. The former can be easily acquired through standard sensors, on the contrary, providing a good evaluation of the physiological variables of the model (i.e. metabolic rate and clothing insulation) is more difficult. In the proposed methodology, a wearable multi-parametric device has been adopted to measure data from occupants and calculate the metabolic rate. Different sets of physiological data have been investigated to derive the optimal set providing the most accurate metabolic rate. Results from laboratory tests are presented, considering activities ranging from sedentary (1 met) to more active ones (4 met). Finally, a virtual test bench has been developed to simulate a building where the methodology proposed is used to control the indoor air temperature by means of a PMV-based set-point calculation. The methodology has then been compared to traditional approaches with constant $M$.
\end{abstract}

Key words: metabolic rate, smart buildings, thermal comfort, wearable sensors

Received: March, 2018; Revised final: June, 2018; Accepted: September, 2018; Published in final edited form: October 2018

\section{Introduction}

Considering that people spend about $90 \%$ of their time in an indoor environment, in the last decades great attention has been paid to the assessment and optimization of the indoor thermal comfort in office buildings. It is well-known that the indoor environment and microclimatic conditions greatly affect the health, well-being and productivity of occupants. This extensive interest can be linked not only to the aspects mentioned above, but also to the establishment of a series of European Directives and international and European Standards aiming at improving the energy and environmental performance of buildings without decreasing occupants' comfort
(Antoniadou and Papadopoulos, 2017). This theme is also interconnected with the necessity of reducing energy consumption in buildings, which should be able to provide the highest indoor comfort with the minimum energy consumption. To this aim, the development of new technologies and services for optimal comfort management are part of the wider context of buildings' efficiency and sustainability. This approach is the basis of the Energy-efficient Buildings Public-Private Partnership (EeB PPP) initiative supported by the EU Commission, where research projects are founded to achieve the EU goals in terms of energy use, decarbonization, sustainability and improved living and well-being, also taking into account particular sectors like the ageing one. In this

*Author to whom all correspondence should be addressed: e-mail: m.arnesano@univpm.it; Phone: +39 0712204508; Fax: +39 0712204801 
context, several projects have been co-founded to support the development of new technologies under 7 technology clusters (from design to ICT). Given the attention to all levels (from building to urban scale), one of the main exploitations of the results of the initiative can be found in the Smart City paradigm, where new services are provided to improve cities in relation to the above-mentioned themes. In this context, thermal comfort is one of the main services that a building should deliver and, today, the need to improve the state-of-the-art methodology used to assure this is particularly strong. For this reason, comfort management should make use not only of environmental parameters but also of parameters related to occupants, which, however, could vary in time and space according to multi-contextual factors (e.g. activity, age, culture, social rules etc.) (Kim et al., 2018). In this context, the use of innovative technologies, most of them coming from ICTs, integrated with existing models and tools can enhance the comfort delivered with reduced environmental impact (Capolongo et al., 2013; Lee et al., 2017; Petri et al., 2015; Revel et al., 2015a; Zampetti et al., 2018). The work presented in this paper wants to address this topic, illustrating an example of how a traditional thermal comfort model can be empowered with the integration of ICT tools, to increase the monitoring and controlling capacity in a building.

As said, thermal comfort is one of the most important factors for the well-being of building occupants. The American Society of Heating, Refrigerating and Air-Conditioning Engineers (ASHRAE) defined thermal comfort as "the condition of the mind in which satisfaction is expressed with the thermal environment''(ASHRAE, 2017). Therefore, according to the above definition, comfort is a subjective sensation.

Thermal comfort is generally measured by sensors compliant with mathematical models that express the overall interaction between human body and the environment (body heat production and exchange, influencing factors, etc.). The most used model is based on Fanger's comfort theory which enumerates six factors to determine heat balance and provides a formula to calculate the PMV (Predictive Mean Vote) index. Four of the six are environmental parameters: relative humidity, air temperature, mean radiant temperature and air velocity. The remaining two are personal factors: metabolic rate and clothing insulation. The PMV measurement thus requires the capability to sense not only the environmental parameters, but also those factors that are related to occupants' characteristics. With regard to the environmental quantities, the microclimate station is the most used device for short-term monitoring. Recently, innovative solutions have been developed to provide measurements with the same level of accuracy, although for real-time and continuous monitoring purposes (Revel et al., 2014a). With regard to the personal factors, recent studies have been carried out to explore the impact of subjective parameters on thermal comfort monitoring, as presented in (Luo et al., 2016), also offering some solutions for the measurement of the metabolic rate (Luo et al., 2018). However, in practical building controls, subjective parameters (which greatly affect thermal comfort) are not considered (thermostats) or are still treated as constants, adopting values from standards and according to the typical end-use of the building. This assumption usually does not reflect real conditions and, therefore, leads to incorrect evaluations. In the view of improving these estimations, this work presents a new methodology for the dynamic measurement of the metabolic rate, making use of wearable sensors based on the methodology presented in (Revel et al., 2015b).

Going beyond the results obtained in the work of (Hasan et al., 2016), the continuous assessment methodology has been tested for the monitoring but also for the comfort management of a building. Thus, attention has been focused on both the integration and the uncertainty of the measurement technique proposed, in order to determine the impact on the PMV-based comfort management. Finally, a virtual test bench has been developed to show the applicability to the real-time control of the HVAC of buildings. Therefore, a simulation model of a building has been used to test a PMV-based air temperature controller, with and without the dynamic metabolic rate method. This test has showed the advantages achievable from using the real-time measurements of the metabolic rate thanks to the reduced uncertainty of the PMV index estimated to control the environment.

\section{Material and methods}

\subsection{Model used for comfort monitoring}

The PMV model aims at predicting the mean thermal sensation of a group of people in the same environment (Fanger, 1970) through a steady-state heat balance model of the human body. The PMV index is a function of air temperature $\left(t_{a}\left[{ }^{\circ} \mathrm{C}\right]\right)$, mean radiant temperature $\left(t_{r}\left[{ }^{\circ} \mathrm{C}\right]\right)$, water vapour partial pressure $p_{a}[\mathrm{~Pa}]$, which, in turn, is a function of the measurement of relative humidity ( $R H$ [\%]), air velocity $\left(v_{a}[\mathrm{~m} / \mathrm{s}]\right)$, clothing insulation $\left(I_{c l}[\mathrm{clo}]\right)$ and metabolic rate $(M$ [met]) and represents the thermal sensation of occupants (Eq. 1):

$$
P M V=f\left(t_{a}, t_{r}, p_{a}, v_{a}, I_{c l}, M\right)
$$

The measurement of the environmental parameters can be easily performed through standard instrumentation such as black-globe thermometers, anemometers, thermistors (e.g. microclimate stations). Moreover, with the recent growth in technologies, new low-cost devices have been developed for the realtime monitoring of ambient parameters, as in (Revel et al., 2014a). On the contrary, personal parameters are difficult to measure. The next Section introduces a new methodology for the integration of the "human dimension" so as to allow a more accurate assessment of thermal comfort. 
2.2. Calibration curves for the real-time measurement of metabolic rate

This section discusses the real-time measurement of the metabolic rate. The goal is to provide an innovative methodology for the dynamic evaluation of $M$ to enhance thermal comfort assessment. The metabolic rate is defined as the amount of daily energy that a person consumes while at rest in an environment that is temperate and neutral and while in a post-absorptive state. The chemical and physical reactions that occur in an organism are reversible and depend on changes in the energy status. Among the parameters affecting indoor thermal comfort, this physiological parameter is one of the most important. In Revel et al. (2014b) a sensitivity analysis of the PMV index was performed to investigate the PMV variation due to the metabolic rate. The authors report that the metabolic rate has a high influence, which increases especially for lower values (<1met). For this reason, having a good estimation of this quantity is important for an accurate estimation of thermal comfort (D'Ambrosio et al., 2011). Small variations of $M$ induce large deviations in thermal sensation.

According to the Standard ISO 8996 (2004), there are several methodologies based on the statistical analyses or measurements of indirect parameters that can be used for the assessment of the metabolic rate. Among these, a methodology based on the continuous monitoring of the subject's heart rate $(H R)$ should be able to provide an estimation of $M$ with an accuracy of $\pm 10 \%$. In (Revel et al., 2015b) a simplified version of the method described above was applied. The results showed that, by applying this method, different activities can be identified, considering the real perception of the subjects in a room.

The new methodology presented in this work is based on continuous multi-parametric measurements to provide a real-time estimation of the metabolic rate. A wearable device (BioHarness 3.0 BH3), as the one described in (Casaccia et al., 2016), was adopted to measure several physical and physiological quantities. Specific information about the validity and reliability of the BH3 device are discussed in (Johnstone et al., 2012a; 2012b), through dedicated laboratory tests.

Referring to Pietroni et al. (2016), different indicators (i.e., IN5, IN4, IN3) which depend on the number of the parameters considered (i.e., the ones measured by the same device) were found Combinations of 5, 4, and 3 parameters (Eqs. 2-4) were evaluated. The index derives from a combination of different parameters acquired with the BH3. The single indicators can be expressed through the relationships reported below, which represent the area of an irregular polygon:

$$
\begin{aligned}
I N 5= & \frac{1}{2} \cdot\left(\left(H R_{n} \cdot B R_{n} \cdot \sin \left(a_{1}\right)\right)+\left(B R_{n} \cdot P O S_{n} \cdot \sin \left(a_{1}\right)\right)+,\right. \\
& \left(P O S_{n} \cdot A C T_{n} \cdot \sin \left(a_{1}\right)\right)+\left(A C T_{n} \cdot A C C_{n} \cdot \sin \left(a_{1}\right)\right), \\
& \left.+\left(A C C_{n} \cdot H R_{n} \cdot \sin \left(a_{1}\right)\right)\right)
\end{aligned}
$$

$$
\begin{aligned}
I N 4= & \frac{1}{2} \cdot\left(\left(H R_{n} \cdot B R_{n} \cdot \sin \left(a_{2}\right)\right)+\left(B R_{n} \cdot A C T_{n} \cdot \sin \left(a_{2}\right)\right),\right. \\
& +\left(A C T_{n} \cdot A C C_{n} \cdot \sin \left(a_{2}\right)\right)+\left(A C C_{n} \cdot H R_{n} \cdot \sin \left(a_{2}\right)\right)
\end{aligned}
$$

$$
\begin{aligned}
& I N 3=\frac{1}{2} \cdot\left(\left(A C T_{n} \cdot H R_{n} \cdot \sin \left(a_{3}\right)\right)+\left(H R_{n} \cdot A C C_{n} \cdot \sin \left(a_{3}\right)\right),\right. \\
& +\left(A C C_{n} \cdot A C T_{n} \cdot \sin \left(a_{3}\right)\right)
\end{aligned}
$$

where: $H R$ is the heart rate [bpm], $B R$ is the breathing rate $[\mathrm{bpm}], P O S$ is the posture of the subject $\left[^{\circ}\right], A C T$ is the activity level [expressed as VMU - Vector Magnitude Units], ACC is the acceleration module [g]. Subscript " $n$ " indicates that values were normalised. The normalisation was calculated for the following range value: $40 \div 240 \mathrm{bpm}$ for $H R, 4 \div 100 \mathrm{bpm}$ for $B R$, $-90^{\circ} \div 90^{\circ}$ for posture, $0 \div 4$ for activity level and $0 \div 6 \mathrm{~g}$ for acceleration module. The angles $a_{1}, a_{2}, a_{3}$ are $72^{\circ}$, $90^{\circ}$ and $120^{\circ}$ respectively.

To verify the feasibility of the approach proposed, a specific test was conducted to identify the most accurate calibration curve for the dynamic evaluation of metabolic rates. As reported in Table 1, ten young and healthy individuals recruited among university students were involved ( 5 females and 5 males, age: $21 \pm 1$ years, weight: $61 \pm 13 \mathrm{~kg}$, height: $1.71 \pm 0.09$ m, BMI: $20.95 \pm 2.72 \mathrm{~kg} / \mathrm{m}^{2}$ ).

Within the tests conducted, the subjects were asked to perform 4 different kinds of activity. Standard ISO 7730 (ISO 7730, 2005) reports that the PMV model returns an estimate of indoor thermal comfort which can be considered reliable for metabolic rate values not exceeding 4 met.

Table 1. Characteristics of the subjects

\begin{tabular}{|c|c|c|c|c|c|}
\hline Subject & Gender & Age [years] & Weight $[\mathbf{k g}]$ & Height $[\mathbf{m}]$ & BMI $\left[\mathbf{k g} / \mathbf{m}^{\mathbf{}}\right]$ \\
\hline 1 & F & 22 & 44 & 1.62 & 16.77 \\
\hline 2 & F & 22 & 56 & 1.63 & 21.08 \\
\hline 3 & F & 21 & 52 & 1.60 & 20.31 \\
\hline 4 & F & 21 & 55 & 1.73 & 18.38 \\
\hline 5 & F & 21 & 70 & 1.73 & 23.39 \\
\hline 6 & M & 19 & 77 & 1.80 & 23.77 \\
\hline 7 & M & 22 & 70 & 1.75 & 22.86 \\
\hline 8 & M & 21 & 58 & 1.68 & 20.55 \\
\hline 9 & M & 21 & 71 & 1.88 & 20.50 \\
\hline 10 & M & 21 & 58 & 1.68 & \\
\hline
\end{tabular}


The standard values chosen to perform the tests are reported in Table 2. Each subject completed the activitiy profiles in 20 minutes and tests were carried out following a well-defined order (i.e., ascending profile of metabolic rate per activity, then descending profile of metabolic rate activity). The acquisition of the physiological quantities of interest was performed on-board by the BH3 device and the quantities computed (e.g., heart-rate, breathing rate, acceleration module, etc.) were directly stored inside the device. The data were post-processed and Fig. 1 shows an example of the time-domain variation of each signal acquired during the tests.
It is possible to observe that both the acceleration and activity signals follow the reference profile (Activity number, as Fig. 1a) with a good approximation. Conversely, the heart rate, breathing rate and posture deviate from the standard (Fig. 1b). This is probably caused by the fact that an increase in metabolic activity is correlated with an increase in these physiological quantities, but these parameters take a longer time to become stable. The same considerations are valid for the descending profile of $M$. A dedicated algorithm for data processing was developed as reported in Fig. 2.

Table 2. Standard value of metabolic rate.

\begin{tabular}{|c|c|c|}
\hline Number of Activity & Activity & Metabolic Rate [met] \\
\hline 1 & sedentary activity & 1.2 \\
\hline 2 & slow walk on the flat & 2.5 \\
\hline 3 & go down the stairs & 3.5 \\
\hline 4 & climbing stairs & 4 \\
\hline
\end{tabular}

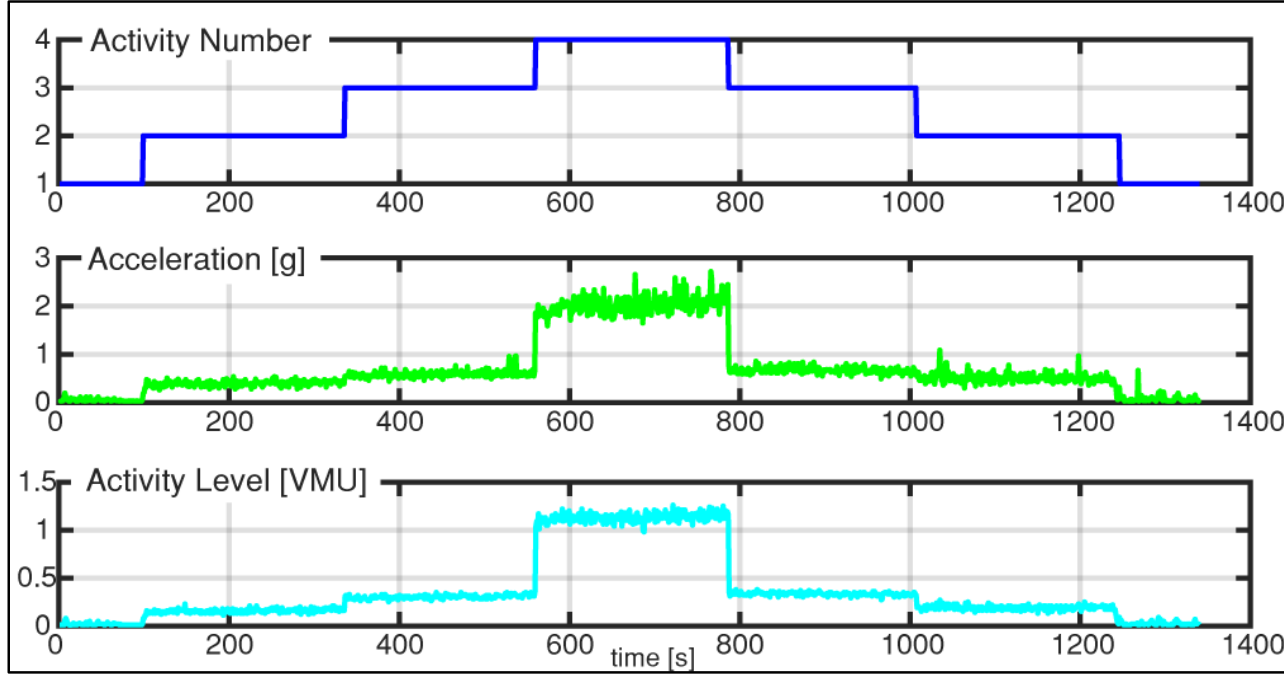

(a)

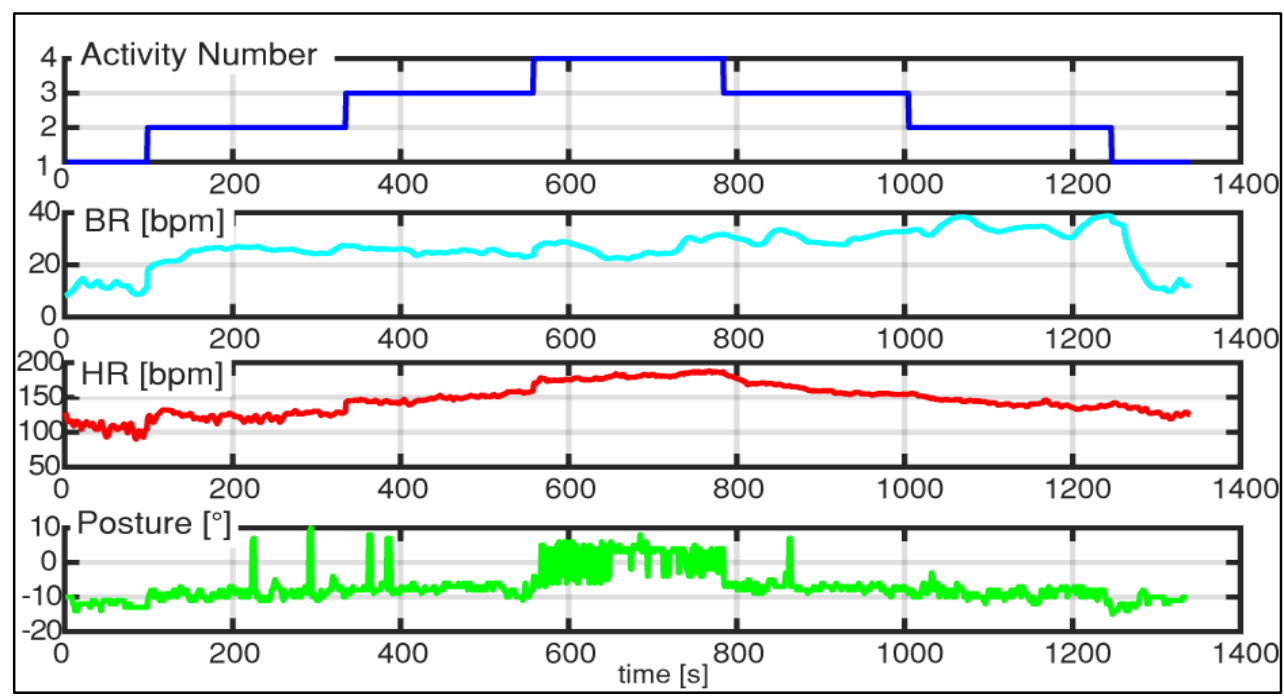

(b)

Fig. 1. (a) Trend of standard-based metabolic rate, acceleration and activity level during the tasks; (b) trend of $\mathrm{BH}, \mathrm{HR}$, and posture during the tasks. 
Initially, for each activity, a portion of the raw data acquired by the BH3 device was selected. The data average was computed, and a first threshold was determined using the Chauvenet's criterion to remove outliers (Lin and Sherman, 2007) (excluding those that were not within the range \pm 3 standard deviation). At this point, the average of the remaining data was recalculated for each single activity performed and a second threshold was applied to remove the outliers through a robust bivariate analysis implemented through a MATLAB toolbox (FSDA - Forward Search for Data Analysis) (Riani et al., 2012). This first step of data processing was applied to all the signals acquired from the respective subjects and for each activity. Fig. 3 reports an example of the data obtained after data processing.

Finally, the indicators expressed by Eqs. (2-4) were correlated with the standard metabolic rate reported in Table 2 and curves for the dynamic evaluation of metabolic activity (Eqs. 5-8) were obtained (Table 3)(Eqs. 5-8).

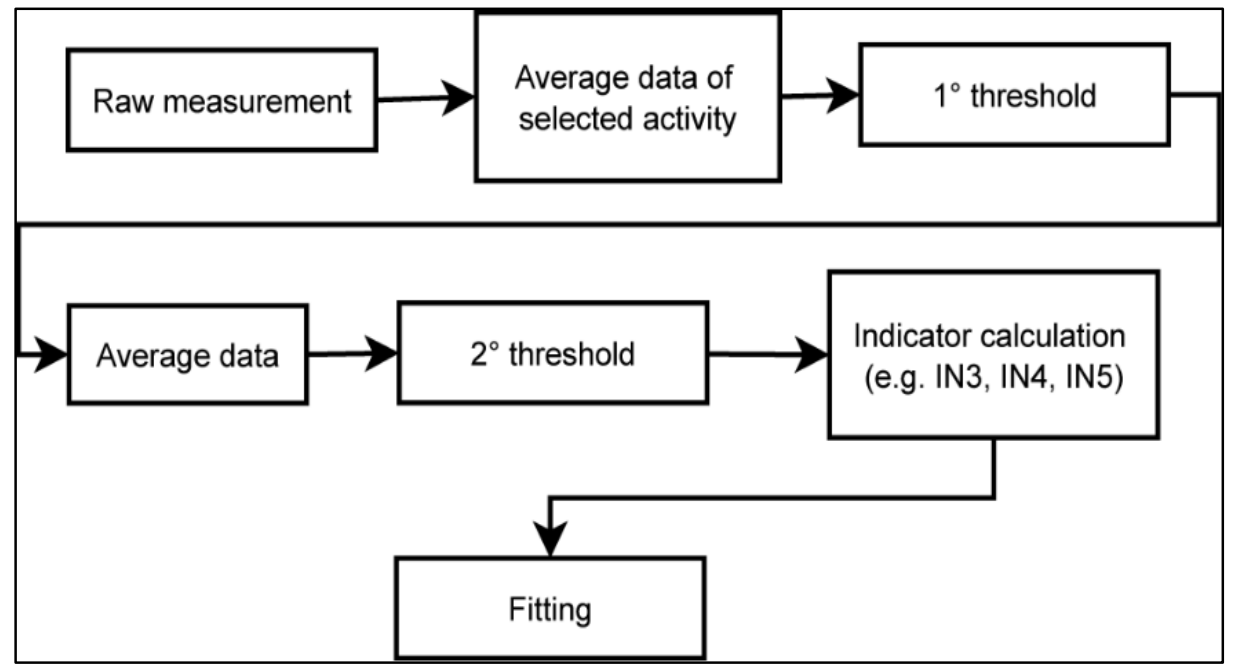

Fig. 2. Scheme of the data processing algorithm.

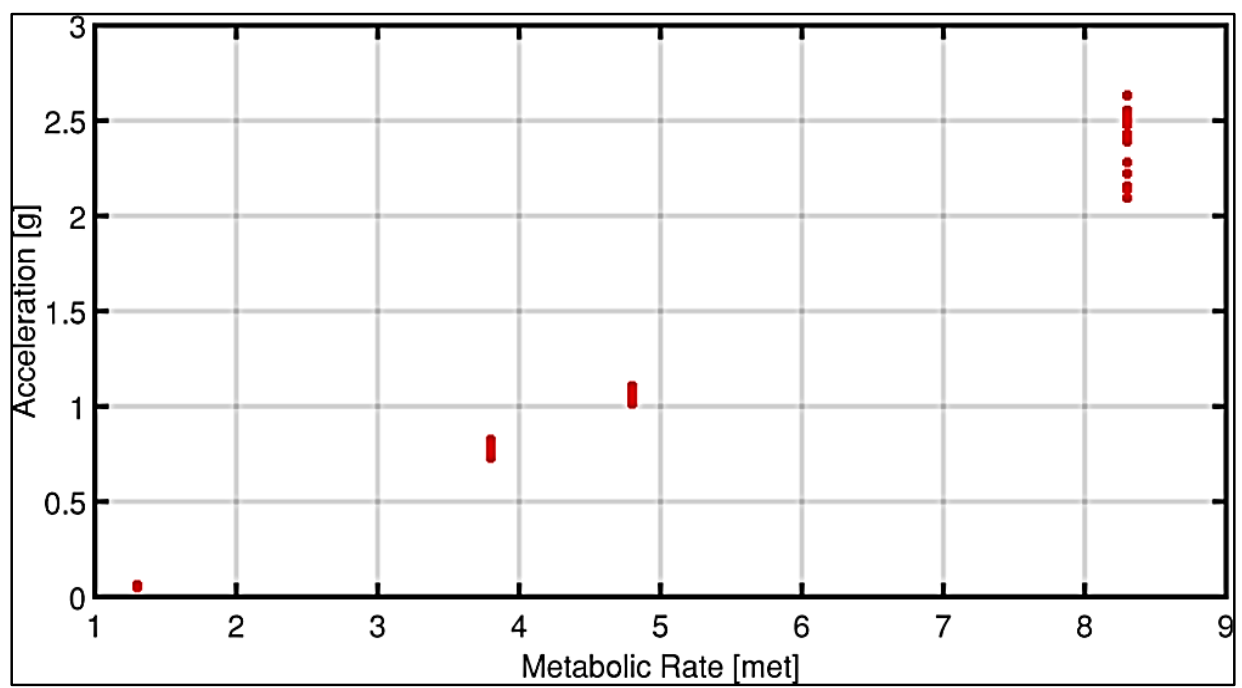

Fig. 3. Example of acceleration data after data processing

Table 3. Relationship for the dynamic evaluation of the metabolic rate based on indicators.

\begin{tabular}{|c|c|c|}
\hline Equations & $R^{2}$ & $R M S E(2 \sigma)$ [met] \\
\hline$M=8.48 \cdot e^{\left(-\frac{I N 5-0.42}{0.27}\right)^{2}}$ & $97 \%$ & 0.48 \\
\hline$M=-17.5+17.9 \cdot \cos (\operatorname{IN} 4 \cdot 2.6)+18.8 \cdot \sin (\operatorname{IN} 4 \cdot 2.6)$ & $96 \%$ & 0.50 \\
\hline$M=\left(1.2+\left(3.4 \cdot\left(1-e^{-62.0 \cdot I N 3}\right)\right)+15 \cdot\left(1-e^{-2.22 e^{-14} \cdot I N 3}\right)\right)$ & $96 \%$ & 0.20 \\
\hline$M=1.88+\left(7.8 \cdot A C C_{n}\right)+\left(-4.4 \cdot H R_{n}\right)+\left(-16.6 \cdot\left(H R_{n}\right)^{2}\right)+\left(21.4 \cdot H R_{n} \cdot A C C_{n}\right)+\left(5.1 \cdot\left(A C C_{n}\right)^{2}\right)$ & $96 \%$ & 0.23 \\
\hline
\end{tabular}


This new methodology provides the curves for the real-time assessment of the metabolic rate expressed as a function of the personal parameters acquired simultaneously. Looking at the results in Table 3, it appears that, to compute an accurate value of $M$, the measurement of the heart rate and physical quantities (i.e., acceleration and $V M U$ index) is needed. This suggests that the computing methodology proposed could be applied to wearable devices (e.g., smartwatches, wearable belts), enabling a real-time $M$ measurement with an uncertainty of \pm 0.2 met. This outcome is referred to the sample population involved and to the activities performed. To achieve a wider applicability, the population should be extended to include subjects with different backgrounds.

\subsection{Test Bench for the simulation model}

The methodology proposed (presented in Section 2.2) was integrated into a virtual environment consisting of a building simulation model with technical systems which allow the control of indoor air temperature by means of a PMV-based approach. In the following, the controller developed is described and the virtual test bench of a house and the integration of the controller are presented.

\subsubsection{Development of the controller based on the PMV virtual sensor}

Generally, performing the standard control of indoor air temperature means to manually set a predefined indoor temperature. However, there is a lot of interest on how to optimise the selection of such setpoint (Dounis and Caraiscos, 2009) also making use of the PMV model, as performed in (Zampetti et al., 2018). To enhance this aspect, in this work an advanced controller (Fig. 4) was developed and tested taking into account the real-time measurements of $M$ as well as the other environmental quantities collected to evaluate comfort conditions. The controller is a Proportional-Integral-Derivative (PID) controller which takes as input the air temperature $\left(t_{a}\right)$ and the set-point temperature $\left(T_{\text {set }}\right)$ calculated with a PMVbased method and provides as output the heat to be supplied to the house.

In this simulation, the winter season was considered. The PID controller regulates the heat required to reach the set-point temperature of the simulated home environment. The set-point temperature used by the PID controller to achieve comfort conditions is determined from a virtual sensor that calculates the PMV. In particular, $T_{\text {set }}$ represents the air temperature which allows the highest level of comfort $(\mathrm{PMV}=0)$. A root finding algorithm was used to obtain the value of $T_{\text {set. }}$ (Eq. 9):

$T_{\text {set }} \mid \operatorname{pmv}\left(T_{s e t}, t_{r}, v_{a}, p_{a}, I_{c l}, M\right)=0$

A Matlab routine based on the Dekker's algorithm, which uses a combination of bisection, secant, and inverse quadratic interpolation methods to find the roots of nonlinear functions (Brent R.P., 2013), was adopted to compute the set-point temperature.

\subsubsection{Integration of the controller into the simulation model}

The simulation model was performed in the Simulink environment. Starting from the basic version of the model of a heating system (provided by Simulink libraries), some modifications were applied to implement a PMV virtual sensor and an air temperature controller based on such virtual sensor, as presented in the previous section.

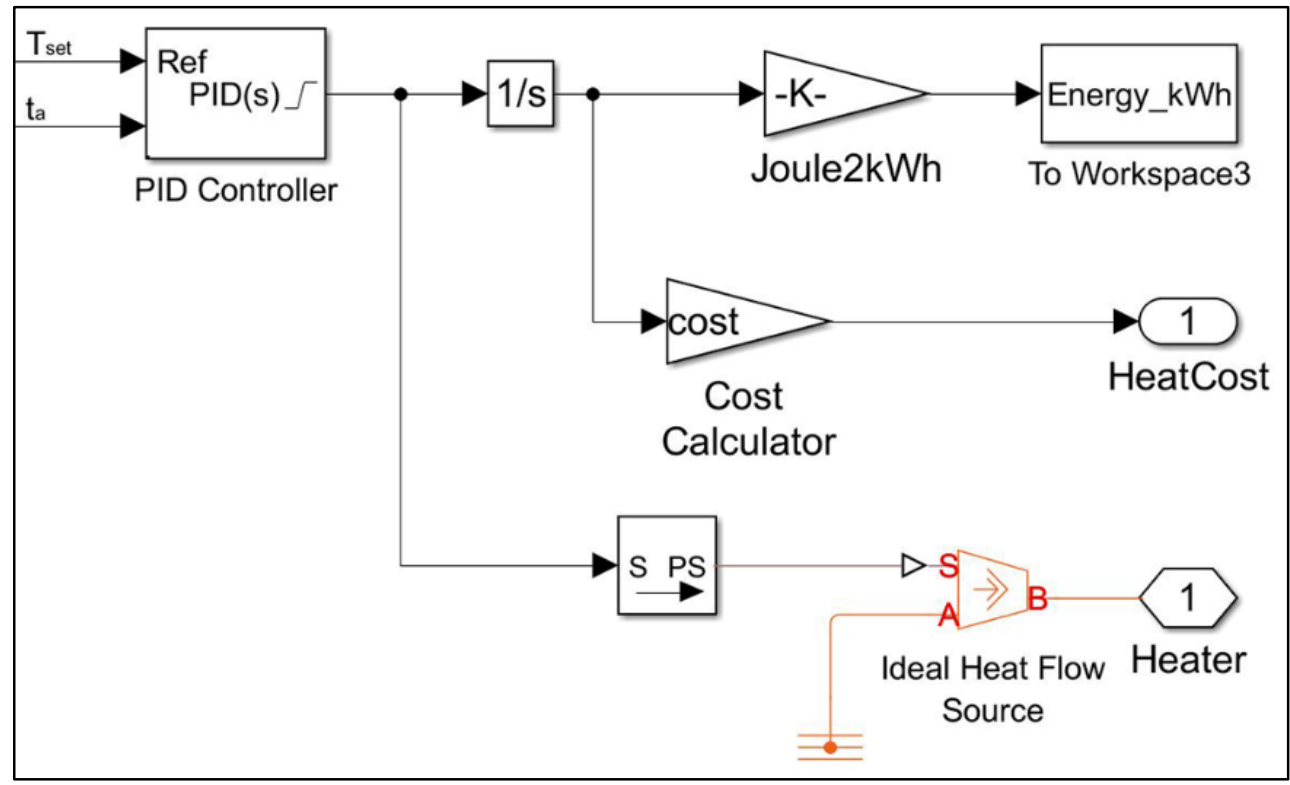

Fig. 4. PID controller applied to the simulation model. 
The PMV virtual sensor was modelled with two different working modes: i) as a traditional sensor, without the real-time metabolic rate measurement; ii) as an innovative system with the real-time measurement of the metabolic rate as proposed in this paper. Thus, the virtual test bench was used to evaluate the impact of the PMV uncertainty on the management of the building as a function of the metabolic rate error that can occur when constant values are used instead of continuous monitoring.

The basic version of the model consists of a heater, a thermostat and a lumped parameter model of the house. The heat exchanges between indoor and outdoor environments through walls, windows and roof were modelled with the electrical-analog method for transient heat-flow, as already done in (Revel et al., 2012). Fig. 5 shows the modified simulation model.

To perform the test, the PID element was integrated into the simulation model of the heating house network. First, the initial value of the air temperature inside the house was set at $23{ }^{\circ} \mathrm{C}$. The heater provides, or does not provide, sensible heat according to the set-point temperature. To run the control algorithm, the computation of the PMV was provided by a virtual sensor that gathered environmental variables from the model. In particular, the air temperature $\left(t_{a}\right)$ was assumed to be equal to the room temperature of the modelled house. Since the simulation approach did not include mass balance and moisture, the air velocity $\left(v_{a}\right)$ was set at a fixed value of $0.02 \mathrm{~m} / \mathrm{s}$ and relative humidity $\left(R_{H}\right)$ at a value varying around $50 \%$ with a uniform distribution with a range of $\pm 2.5 \%$.

Given that the simulation was performed for the heating season, the clothing insulation $\left(I_{c l}\right)$ was fixed at 0.85 clo. Finally, the evaluation of the mean radiant temperature $\left(t_{r}\right)$ was done with the angle factor methodology in agreement with the ISO 7726 (ISO $7726,1998)$. The mean radiant temperature was computed from the indoor surface temperatures of the room and weighted with the view factors calculated for a central position of a subject with respect to the surrounding walls.

During the simulation, the virtual sensor calculated the PMV index continuously and, consequently, the set-point temperature was computed according to Eq. (9).

\section{Results and discussion}

This Section discusses the results obtained from the two simulated tests adopting the model described in the previous paragraph. In both tests, an indoor temperature control was performed, based on a set-point temperature (i.e., derived from a PMV index). The difference was in the $M$ parameter, which is one of the six quantities for the calculation of the PMV value. In the first case, a dynamic profile of $M$ was considered (i.e., the time-dependent value obtained with the wearable sensor and the application of the methodology previously discussed). The second case refers to a constant profile of $M$ (i.e., a fixed value for the entire duration of the test, as generally done in the state of the art).

In this experiment, a typical 8-hour working day was simulated. The dynamic profile of the metabolic rate was modelled considering the activities which can be performed during the working hours. The metabolic rate profile used for both tests is shown in Fig. 6. The profile simulated an initial activity typical of office work (1.2 met) with a gradual increase in the metabolic rate reaching 1.6 met, which corresponds to standing activities, and, after keeping this rate for 4 hours, the profile returned to the initial value. The values of $M$ were derived from the compendium of metabolic activities provided by ISO7730 (2005). Fig. 7 shows the trends of the setpoint and air temperatures when performing control strategy with a dynamic $M$ (Fig. 7a) and with a constant $M$ (Fig. 7b). As said in Section 2.3.1, the setpoint temperature depends on the PMV evaluation, which is significantly affected by the metabolic rate.

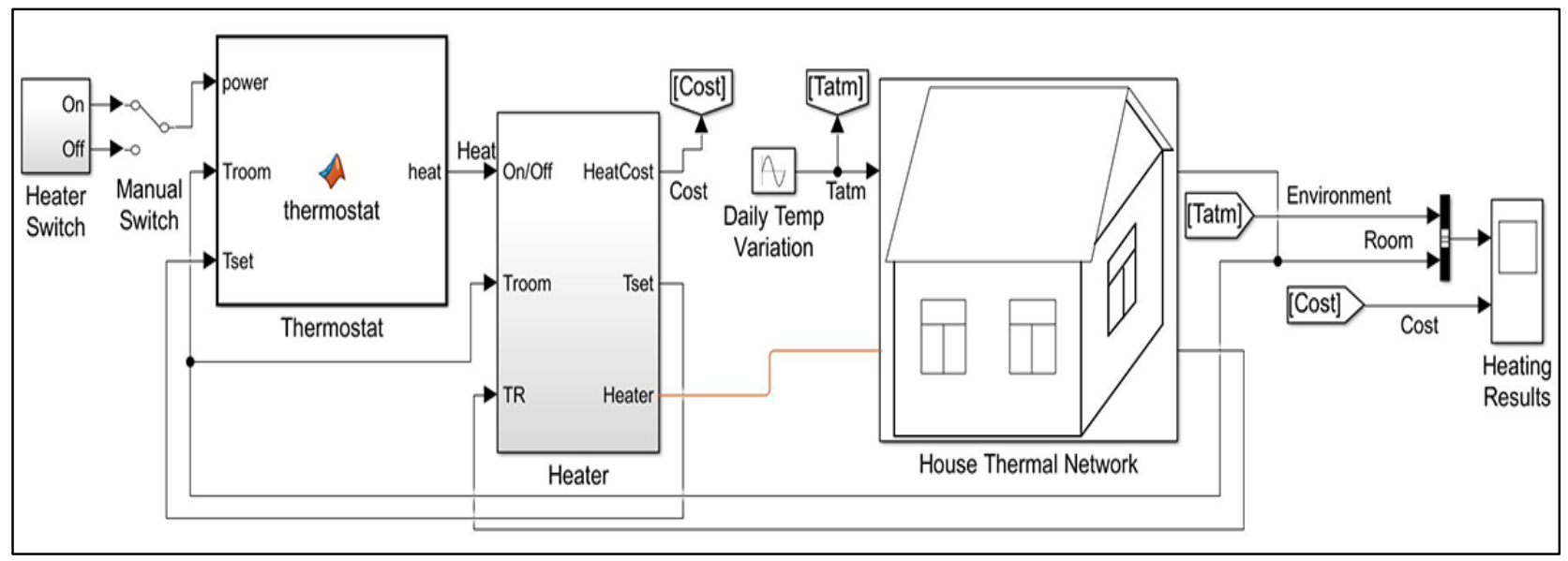

Fig. 5. Simulation model for the Heating house network. 


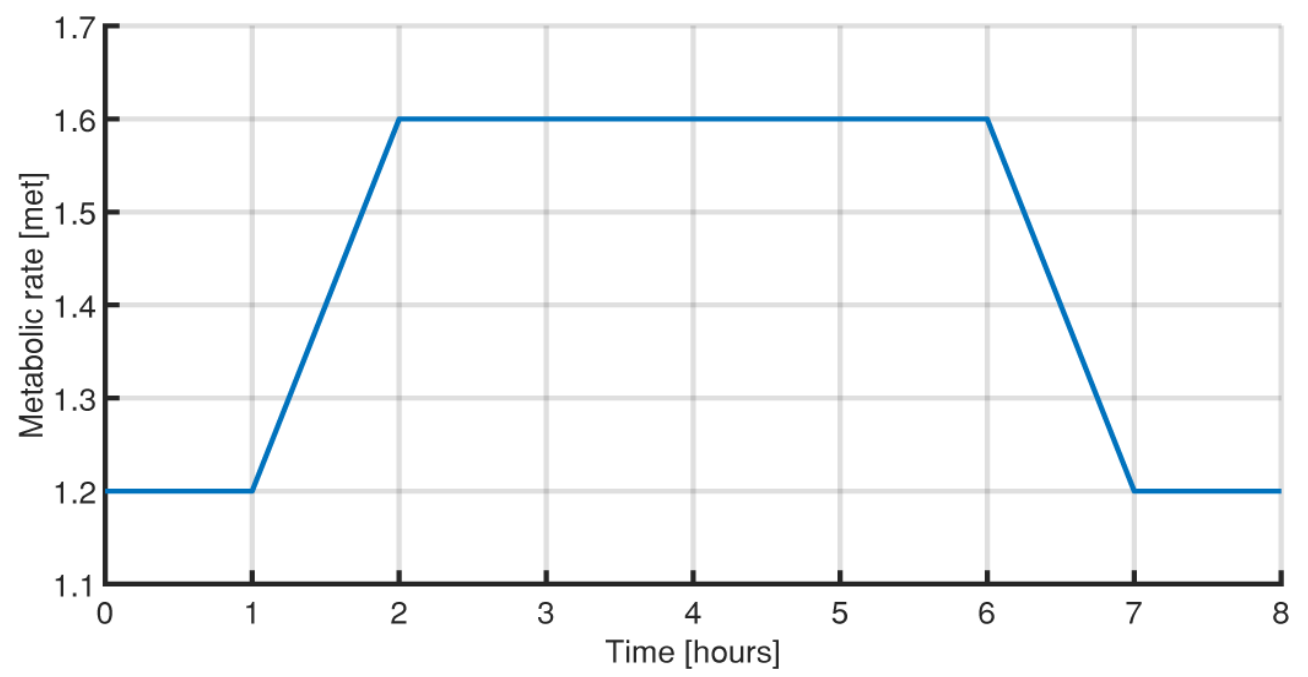

Fig. 6. Dynamic profile for the metabolic rate adopted in the simulation

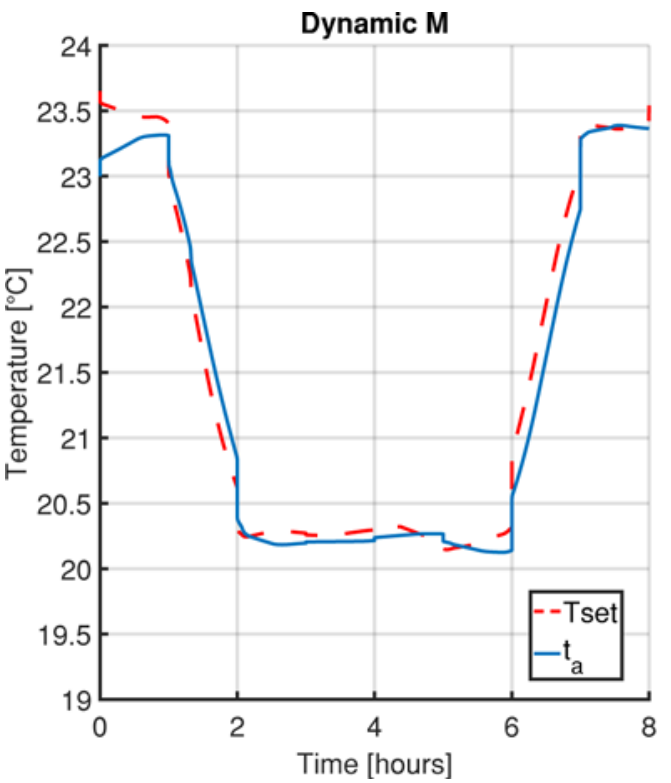

(a)

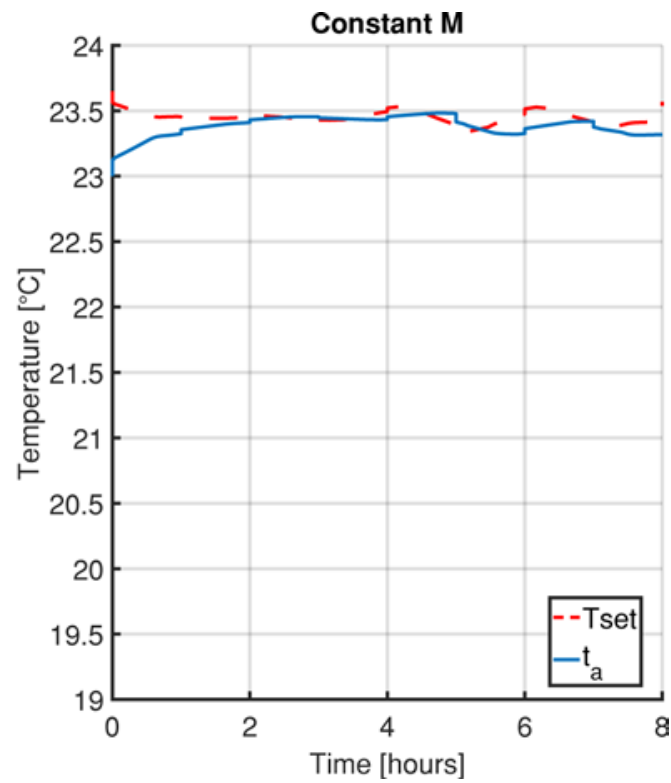

(b)

Fig. 7. Trends of the set-point temperatures and the air temperatures obtained by performing the two different controls:

(a) with a dynamic profile of the metabolic rate; (b) with a constant value of the metabolic rate

It is possible to observe that, in winter conditions, when implementing a control strategy that uses a constant value of $M$ (Fig. 7b), the indoor air temperature is kept almost constant. The heater provides continuous heat to the environment, while the real need of the occupant would be having a lower air temperature, as shown in Fig. 7a, where the use of a dynamic $M$ for the set-point calculation provided a variation of $T_{\text {set. }}$. In fact, an increase in $M$ induces an increase in energy production by the human body that turns out to provide a lower comfort air temperature, therefore a lower $T_{\text {set }}$. The set-point temperature gradually decreased as a function of the metabolic rate increase. Conversely, when the metabolic rate decreased, the system responded correctly by calculating a higher set-point temperature to restore the comfort condition. Comparing the two situations of the case study proposed, the use of a constant metabolic rate instead of real-time monitoring led to an error in the PMV calculation propagated as an error of $3.2^{\circ} \mathrm{C}$ in the calculation of $T_{\text {set }}$. This error provided an impact in terms of comfort delivered to the occupants and efficiency in the management of the building. Analysing the PMV calculated by the virtual sensor in both tests, the control based on a dynamic $M$ provided an average PMV close to zero (mean value of PMV: 0.03 \pm 0.09 ; Fig. 8a - Dynamic $M$ ). Conversely, the control with a constant value of $M$ (Fig. 8a - Constant $M$ ) turned out to provide an environment near to the slightly warm sensation (mean value of PMV: $0.3 \pm 0.3$ ). This happened because the controller was not able to recognize the lower heating needs due to the increased occupants' activity.

As a consequence, overheating occurred, which turned out to provide worse comfort conditions 
with higher energy consumption, as demonstrated in Fig. 8b, where the energy consumptions recorded with a dynamic $M$ (Fig. 8b - Dynamic $M$ ) and with a constant value of $M$ (Fig. $8 \mathrm{~b}$ - Constant $M$ ) are reported. The first simulation (dynamic $M$ ) turned out to have an energy consumption of $5.8 \mathrm{kWh}$ against the $8.6 \mathrm{kWh}$ of the second test (constant $M$ ).

This result leads to the conclusion that the monitoring of occupants' activity optimized the comfort management and produced a gap of energy consumption between the ideal control of the heating system and the traditional one. In the case proposed, a gap of $33 \%$ of energy saving was registered.

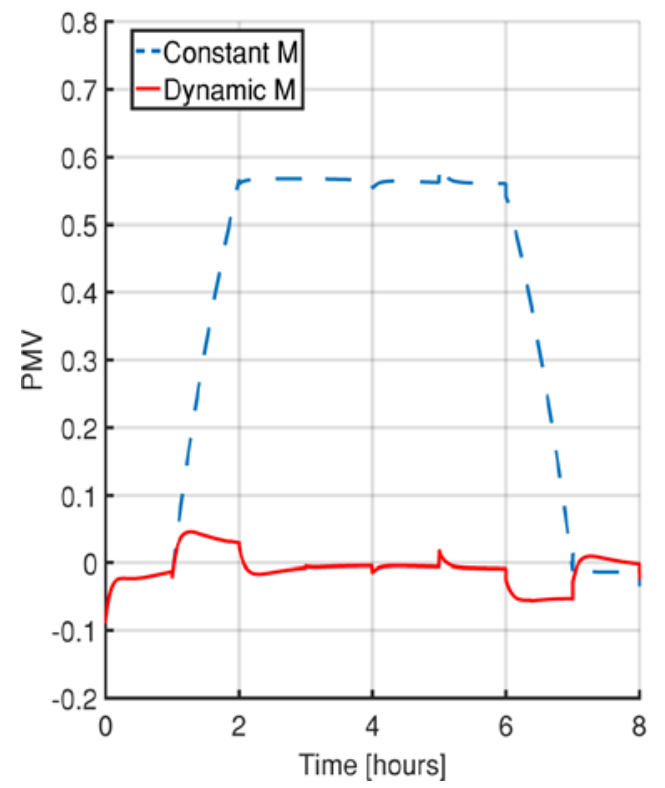

(a)

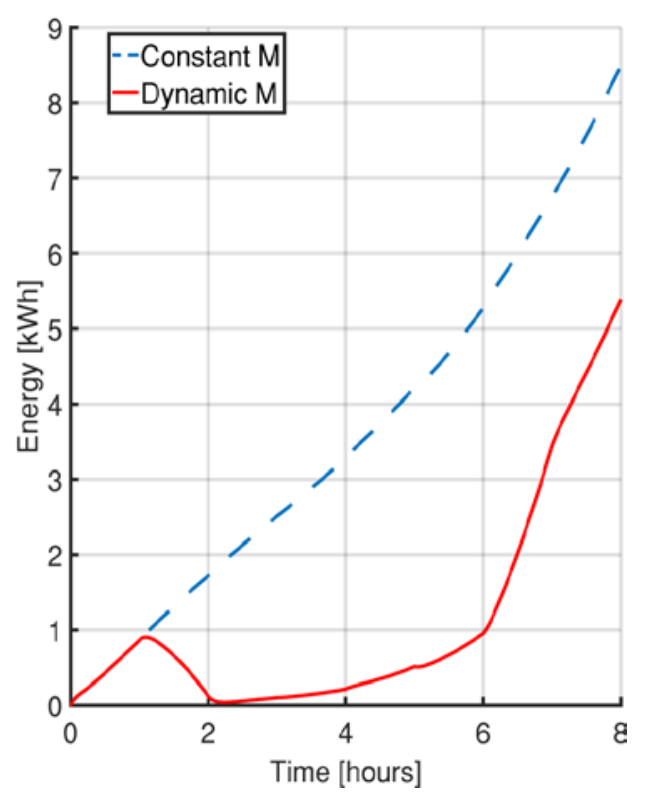

(b)

Fig. 8. (a) Trends of the PMV obtained by performing both the simulation cases;(b) energy consumption obtained by performing both control algorithms with a dynamic $\mathrm{M}$ and a constant $\mathrm{M}$

\section{Conclusions}

Providing comfortable environments is a key aspect to enhance well-being and productivity of building occupants. In this perspective, this work investigates how the employment of wearable devices could improve the use of Fangers' model when applied to real-time monitoring and control, when the possibility to measure physiological parameters to estimate occupants' activity is given. To this end, a new methodology that allows the real-time measurement of the metabolic rate $M$ has been developed.

A wearable device, which provides simultaneous acquisition of physiological quantities, has been adopted and different indicators have been obtained as a function of the number of physiological parameters taken into consideration. Finally, the curves to estimate the metabolic rate depending on the indicators IN5, IN4, IN3 have been obtained. The measurement technique proposed provided an uncertainty of \pm 0.2 met, referring to the sample population and the tasks conducted in the experiment presented. To test its potential use in building operation (monitoring and control), a test has been performed in a virtual environment to compare the results obtained by adopting a PMV-based approach to control the indoor air temperature in two different cases. Two simulations have been conducted for the heating season: one using a controller based on a dynamic $M$ profile and another one based on a static $M$. In both tests, the occupants' activity has been simulated for a profile ranging from 1.2 met to 1.6 met. The results have showed that, under the conditions of the test proposed, the use of a constant $M$ provided an error of $3.2^{\circ} \mathrm{C}$ in the calculation of the PMV-based comfort temperature with respect to the calculation performed with a dynamic $M$, with a consequent condition of overheating and a gap between ideal and actual management in the order of $32 \%$. Thus, the integration of the real-time metabolic rate measurement into PMV-based controllers could reduce the systematic error introduced by the standard and constant activity value assigned to a building. The benefit of the approach proposed has been demonstrated in terms of improved comfort delivered to the occupants and optimised building energy management.

To validate the preliminary results obtained in this work, further research will be carried out taking into account a wider sample population (i.e., in terms of age and contextual factors). Moreover, considering that the wearable device adopted in the tests is accurate but expensive, and generally not used by occupants in daily life, different solutions (e.g., smartwatches) will be tested with the proposed methodology.

\section{References}

Antoniadou P., Papadopoulos A.M., (2017), Occupants' thermal comfort: State of the art and the prospects of 
personalized assessment in office buildings, Energy and Buildings, 153, 136-149.

ASHRAE, (2017), Thermal environmental conditions for human occupancy, Standard 55-2017, American Society of Heating, Refrigerating and Air-Conditioning Engineers, Atlanta, On line at: https://www.ashrae.org/technicalresources/bookstore/standard-55-thermalenvironmental-conditions-for-human-occupancy.

Brent R.P., (2013), An algorithm with guaranteed convergence for finding a zero of a function, On line at: https://maths-people.anu.edu.au/ brent/pd/rpb005.pdf.

Capolongo S., Buffoli M., Oppio A., Nachiero D., Barletta M.G., (2013), Healthy indoor environments: How to assess health performance of construction projects, Environmental Engineering and Management Journal, 12, 209-212.

Casaccia S., Pietroni F., Calvaresi A., Revel G.M., Scalise L., (2016), Smart Monitoring of User's Health at Home: Performance Evaluation and Signal Processing of a Wearable Sensor for the Measurement of Heart Rate and Breathing Rate, Proc. 9th Int. Joint Conf. on Biomedical Engineering Systems and Technologies, Rome, vol. 4, 175-182.

D’Ambrosio F.R.A., Palella B.I., Riccio G., (2011), The role of measurement accuracy on the thermal environment assessment by means of PMV index, Building and Environment, 46, 1361-1369.

Dounis A.I., Caraiscos C., (2009), Advanced control systems engineering for energy and comfort management in a building environment-A review, Renewable and Sustainable Energy Reviews, 13, 12461261.

Fanger P.O., (1970), Thermal Comfort. Analysis and Applications in Environmental Engineering, Danish Technical Press, Copenhagen, Denmark.

Hasan M.H., Alsaleem F., Rafaie M., (2016), Sensitivity study for the PMV thermal comfort model and the use of wearable devices biometric data for metabolic rate estimation, Building and Environment, 110, 173-183.

ISO 7726, (1998), Ergonomics of the thermal environmentInstruments for measuring physical quantities, ISO 7726, International Standard Organization, Geneva, On line https://www.sis.se/api/document/preview/615884/.

ISO 7730, (2005), Ergonomics of the enviroment. Analytical determination and interpretation of the thermal comfort using calculation of the PMV and PPD indices and local thermal comfort criteria, ISO 7730, Internation Standard Organization, Geneva, On line at: https://www.sis.se/api/document/preview/907006/.

ISO 8996, (2004), Ergonomics of the thermal environment determination of metabolic rate, ISO 8996, International Standard Organization, Geneva, On line at: https://www.sis.se/api/document/preview/905211/.

Johnstone J.A., Ford P.A., Huges G., Watson T., Garrett A.T., (2012a), BioHarness ${ }^{\mathrm{TM}}$ multivariable monitoring device: part. I: validity, Journal of Sports Science and Medicine, 11, 400.

Johnstone J.A., Ford P.A., Huges G., Watson T., Garrett A.T., (2012b), BioHarness ${ }^{\mathrm{TM}}$ Multivariable Monitoring Device: Part. II: Reliability, Journal of Sports Science and Medicine, 11, 409.
Kim J., Schiavon S., Brager G., (2018), Personal comfort models - A new paradigm in thermal comfort for occupant-centric environmental control, Building and Environment, 132, 114-124.

Lee Y.Y., Din M.F.M., Ponraj M., Noor Z.Z., Iwao K., Chelliapan S., (2017), Overview of urban heat island (UHI) phenomenon towards human thermal comfort, Environmental Engineering and Management Journal, 16, 2097-2111.

Lin L., Sherman P.D., (2007), Cleaning Data the Chauvenet Way, Proc. SouthEast SAS Users Group, Hilton Head, $1-11$.

Luo M., Zhou X., Zhu Y., Sundell J., (2016), Revisiting an overlooked parameter in thermal comfort studies, the metabolic rate, Energy and Buildings, 118, 152-159.

Luo M., Wang Z., Ke K., Cao B., Zhai Y., Zhou X., (2018), Human metabolic rate and thermal comfort in buildings: The problem and challenge, Building and Environment, 131, 44-52.

Petri I., Rezgui Y., Beach T., Li H., Arnesano M., Revel G.M., (2015), A semantic service-oriented platform for energy efficient buildings, Clean Technologies and Environmental Policy, 17, 721-734.

Pietroni F., Casaccia S., Revel G.M., Scalise L., (2016), Methodologies for Continuous Activity Classification of User Through Wearable Devices: Feasibility and Preliminary Investigation, IEEE Sensors Applications Symposium (SAS), Catania, Italy, 1-6.

Revel G.M., Sabbatini E., Arnesano M., (2012), Development and experimental evaluation of a thermography measurement system for real-time monitoring of comfort and heat rate exchange in the built environment, Measurement Science and Technology, 23, 035005.

Revel G.M., Arnesano M., Pietroni F., (2014a), Development and validation of a low-cost infrared measurement system for real-time monitoring of indoor thermal comfort, Measurement Science and Technology, 25, 085101.

Revel G.M., Arnesano M., Pietroni F., (2014b), A Low-Cost Sensor for Real-Time Monitoring of Indoor Thermal Comfort for Ambient Assisted Living, Proc. Ambient Assisted Living Italian Forum 2013, Ancona, 3-12.

Revel G.M., Arnesano M., Pietroni F., Frick J., Reichert M., Schmitt K., Huber J., Ebermann M., Battista U., Alessi F., (2015a), Cost-effective technologies to control indoor air quality and comfort in energy efficient building retrofitting, Environmental Engineering and Management Journal, 14, 1487-1494.

Revel G.M., Arnesano M., Pietroni F., (2015b), Integration of Real-Time Metabolic Rate Measurement in a LowCost Tool for the Thermal Comfort Monitoring in AAL Environments, Biosystems and Biorobotics, 11, 101110.

Riani M., Perrotta D., Torti F., (2012), FSDA: A MATLAB toolbox for robust analysis and interactive data exploration, Chemometrics and Intelligent Laboratory Systems, 116, 17-32.

Zampetti L., Arnesano M., Revel G.M., (2018), Experimental testing of a system for the energyefficient sub-zonal heating management in indoor environments based on PMV, Energy and Buildings, 166, 229-238. 